\section{Después del Imperio Romano y antes del año mil: morfología urbana, técnicas constructivas y producciones cerámicas}

Agustín Azkarate Garal-Olaun, José Luis Solaun Bustinza Unidad Asociada CSIC/Universidad del País Vasco. Grupo de Arqueología Tardoantigua y Medieval. Arqueología de la Arquitectura (GATMAA)

\section{Resumen}

Este trabajo, circunscrito al reducido marco de los dos pósters que se presentaron en el Seminario Internacional de Arqueología de la Arquitectura (Arquitectura doméstica medieval I, II), constituye un avance de un libro que verá la luz en verano de $2004{ }^{1}$. El objetivo, en consecuencia, no es otro que mostrar de una manera muy breve y desde tres ópticas diferentes pero consustanciales -morfología urbana, técnicas constructivas y producciones cerámicas-, la evolución del poblamiento a lo largo de los siglos tardoantiguos y altomedievales. Tanto en su fondo como en su forma adquirirá, por tanto, un tono forzosamente sintético y simplificado, reduciendo al máximo el aparato crítico y otros recursos bibliográficos.

Palabras clave: Poblamiento; morfología urbana; técnicas constructivas; cerámicas; Tardoantigüedad; Altomedievo.

\section{Abstract \\ This work, circumscribed to the reduced context of the two posters presented at the International Seminar of Archaeology of Architecture (Domestic Medieval Architecture I,II) constitutes an advance of a book to be published in summer, 2004. The objective, consequently, is no other than to show briefly and from three different but consubstantial viewpoints - urban morphology, construction techniques and ceramic production - the evolution of settlements from the late-antique centuries to the high-medieval centuries. The work as a result takes on a necessarily synthetic and simplified tone, reducing to a minimum the critical apparatus and other bibliographic resources.}

Key Words: Settlement; urban morphology; construction techniques; ceramics; late antiquity; high medieval.

\section{LATARDOANTIGÜEDAD}

1.1. En el estado actual de nuestros conocimientos sobre los siglos VI y VII puede parecer una temeridad el tratar de efectuar un avance sobre el poblamiento rural de aquellas centurias. Las investigaciones que se están llevando a cabo desde el Área de Arqueología de la Universidad del País Vasco durante estos últimos años han comenzado, sin embargo, a ofrecer sus primeros frutos. $\mathrm{Y}$ aunque los datos no son todavía suficientes para dibujar un cuadro coherente, pueden servirnos para apuntar, de manera provisional, un primer boceto.

Parece cada vez más claro que debemos contemplar el siglo VI como un momento de transición entre el fin de un periodo que se inició a finales de la centuria anterior con la crisis del sistema productivo romano y otro (que para nuestro ámbito puede situarse en el siglo VIII) caracterizado por la progresiva aparición de asentamientos campesinos estables. En medio — siglos VI y VII — se van a producir una diversidad de situaciones que aconseja no ser excesivamente mecanicistas en la aplicación de determinados modelos interpretativos. Creemos, por ejemplo, que en ocasiones se exagera a la hora de dibujar, para el siglo VI, una ruptura radical respecto de los patrones de asentamiento de época romana, porque aún siendo ésta básicamente cierta para las villae, no lo es tanto para otro tipo de asentamientos, como vienen a demostrar algunos ejemplos alaveses en proceso de investigación. Estamos convencidos de que el punto de partida sobre el que se articuló la transición al altomedievo configuraba una situación mucho más calidoscópica de lo que algunos han imaginado. La pervivencia, en el siglo VI, de productos cerámicos que reflejan el mantenimiento de un comercio todavía activo apunta en esta dirección.

Tampoco es cierto que los hábitos funerarios de los siglos VI y VII se expresen únicamente mediante grandes necrópolis ubicadas en una posición central respecto a diversos asentamientos más o menos alejados y convertidas, de esta manera, en escenario simbólico de rivalidad y emulación social («the cemetery as an arena for competitive discourse, with the burials as statements» en palabras de G. Halsall - 1995: 248-). Ya apuntaba P. Perin en fechas recientes que los casos de cementerios comunes a diversos hábitats no constituyen la regla (1998: 171) y, desde luego, no parece constituirla tampoco en nuestro territorio. Eso se deduce, al menos, de las diversas situaciones que se observan

\footnotetext{
1 A. Azkarate, J.L. Solaun, Investigaciones arqueológicas en el núcleo fundacional de Vitoria-Gasteiz, 2004. Queremos agradecer al prof. Ernesto Pastor el tiempo que ha dedicado a la lectura de este texto y sus inestimables opiniones sobre el mismo. Otro tanto cabe decir respecto a Ismael García, autor de los dibujos que ilustran este trabajo.
} 
en los ritos funerarios, con cementerios «en plein champ» como Aldaieta, San Pelayo o Buzaga, cementerios urbanos como Obietagaña en Pamplona, enterramientos en cueva como en Los Goros, agrupaciones familiares como el caso probable de Guereñu, pequeños núcleos cementeriales sobre necrópolis de época romana como en Finaga, etc. (AzKarate, 2004). Conviene, por tanto, ser cautos y potenciar entre tanto las investigaciones locales y regionales.

1.2. Volviendo al tema del hábitat, recordamos cómo — hace ya quince años- dábamos a conocer nuestro primer trabajo sobre el extraordinario complejo de cuevas artificiales existente en el Condado de Treviño y el occidente alavés. En aquel entonces contextualizábamos nuestro trabajo en el debate existente sobre el proceso de cristianización del País Vasco y priorizábamos, en consecuencia, los aspectos relacionados con su carácter eremítico. Ya para aquellas fechas, sin embargo, apuntábamos la necesidad de «evitar las generalizaciones referidas a la cronología de las cuevas artificiales». E insistíamos en este punto ante la sistemática referencia a esta cuestión "como si de un problema unitario se tratase, aplicando al centenar largo de cavidades los mismos criterios funcionales y cronológicos» (AZKARATE, 1988: 479-480). Observábamos, efectivamente, que «la diferencia entre unos grupos y otros es suficientemente significativa como para que respondan todas ellas a unas mismas circunstancias históricas»y, en consecuencia, aceptábamos el carácter eremítico y la cronología tardoantigua sólo para los núcleos de Faido (San Julián y N. ${ }^{a}$ S. ${ }^{a}$ de la Peña), Albaina (Sarracho y Montico de Charratu) y Laño (Las Gobas y Santorkaria). "No existe, en cambio, dato alguno - ni arqueológico, ni morfológico, ni epigráfico- para defender la coetaneidad de las restantes cavidades del oriente alavés». (Ibidem: 480).

Hoy en día, mantendríamos sustancialmente lo dicho. Las iglesias absidadas y contrabsidadas, las manifestaciones epigráficas con sus invocaciones y aclamaciones, invitan a seguir pensando en un origen eremítico de los conjuntos indicados. Que desde el mismo momento de su creación y, sobre todo, a partir del siglo VII u VIII se convirtieron en polos de atracción de poblaciones campesinas es más que probable, como es muy probable también que este fenómeno tuviera relación con la expansión de la cristianización del mundo rural y el desarrollo agrícola que parece apuntarse a partir de finales del siglo VII. Y, desde luego, es seguro que en el caso de Faido y Laño, estos hábitats rupestres se abandonaron hacia los siglos XI-XII trasladándose su población a nuevas aldeas fundadas en sus proximidades (al fondo del valle en el caso de Laño y en sus inmediaciones en el de Faido) ${ }^{2}$. Los complejos rupestres, abandonados ya como lugares de habitación, se transformaron en adelante en cementerios de los nuevos núcleos rurales.

Este tipo de hábitat rupestre, relegado a zonas marginales, coincidió —en unos tiempos de debilidad demográfica - con otros tipos de asentamiento de los que, sin embargo, sabemos muy poco todavía y que sólo recientemente están aflorando en las investigaciones arqueológicas en curso.

1.3. Las cerámicas, una vez convertidas en indicadores cronológicos fiables (tarea ésta ardua y complicada) pasan a ser unos magníficos indicadores de otras realidades socioeconómicas, aportándonos datos de inestimable importancia sobre la mayor o menor articulación de redes comerciales y su diverso alcance.

En lo que respecta a nuestro territorio, los resultados que paulatinamente se van alcanzando apuntan en la misma dirección que observamos en otros territorios europeos. Sabemos que el siglo VI se va a caracterizar por una progresiva desaparición de las series de cerámica romana (terra sigillata e imitaciones de terra sigillata) en beneficio de las producciones comunes de carácter local, representadas principalmente en un tipo cerámico caracterizado por sus pastas groseras, elaboradas a mano/torneta en sencillos hornos descubiertos y escaso repertorio formal (AzKaraTe, NúNEEZ, SOLAUn, 2003). Este proceso culminará durante la siguiente centuria con el predominio absoluto de este tipo de cerámica grosera, caso de la necrópolis de Aldaieta, y se mantendrá hasta bien entrado el siglo VIII, momento en el que parecen introducirse dos nuevas producciones cerámicas, como explicaremos en la fase siguiente: la cerámica micácea y la cerámica desgrasada con silicatos.

La presencia de producciones cerámicas finas (aunque en fase regresiva) refleja el carácter de transición que apreciamos también en las escasas noticias referidas sobre núcleos de habitación, compartiendo el mismo contexto de desestructuración de los diversos sistemas productivos. En este contexto - ya a partir del siglo VII- las únicas producciones que subsistirán serán aquellas que responden a sistemas productivos de tecnología elemental, en los que la actividad artesanal muestra un alto grado de autosuficiencia y unos modos productivos adaptados a unas circunstancias socioeconómicas nuevas que generan el recurso a ciclos productivos de menor especialización. Todo ello deriva en

2 Ambas figuran en la Reja de San Millán: la primera con la grafía Langu (Layno en la nómina calagurritana de 1257) y la segunda con la grafía Paldu. 
una disminución y simplificación de los tipos de producción cerámica, originando una diversidad regional mucho más marcada que en periodos anteriores.

\section{EL ALTOMEDIEVO}

2.1. Si es cierto que «il pasaggio dall'insediamento sparso ad agglomerato" debe considerarse - tal y como parece que van confirmando las investigaciones arqueológicas- como el "primo segno dell'altomedioevo" (VAlENTI, 1996: 99), este tránsito debería situarse, en lo que respecta a nuestro territorio, a lo largo del siglo VIII. Efectivamente, este siglo - y con seguridad la centuria siguiente- parecen revelarse cada vez con más claridad como un momento de gran importancia en la configuración del poblamiento rural de nuestro ámbito geográfico. El caso de Gasteiz constituye un buen ejemplo de un fenómeno bien conocido en Europa: nos referimos a la sedentarización de poblaciones campesinas en un asentamiento estable que perdurará, con frecuencia, hasta nuestros días. Sus antecedentes se remontan en algunos lugares al siglo VII y, entre otras razones de este fenómeno, hay que mencionar el abandono por parte de las aristocracias locales de los cementerios «en plein champ" característicos de la sexta centuria para crear sus propios ámbitos funerarios en torno a una iglesia de fundación propia que, con el tiempo, acabará atrayendo a sus inmediaciones no sólo al viejo ámbito cementerial sino al propio hábitat campesino.

Lo cierto es que ya desde el siglo IX la documentación de nuestro territorio está reflejando una progresiva densificación de los asentamientos. Es conocida la temprana presencia de un obispo Juan y un abad Avito como protagonistas activos de importantes fundaciones en Valpuesta y Tobillas. La presencia de ciclos constructivos complejos —cantería, bóveda sobre pechinas, etc.-, bien constatada en la primera fase de Tobillas, refleja la capacidad excedentaria de estos primeros grupos dirigentes.

Pero ni son sólo eclesiásticos los personajes que asoman a la documentación ni ésta queda estrictamente circunscrita al área occidental del territorio alavés. Al norte de la llanada alavesa, en las estribaciones del Gorbea, un documento del año 781 recoge una donación efectuada a la iglesia de San Vicente de Acosta en la que figuran un senior Arroncio, un dompno Vitulus, una dompna Obtavia, personajes civiles de relevancia social a juzgar por el tratamiento que reciben. Como ha resaltado García de Cortázar, es importante reseñar que fueron seniores et principes terrae et omnes populi quienes confirmaron esta donación (1982, 94), revelándonos la existencia de estos seniores terrae que, con frecuencia aparecerán en la documentación de la llanada central y oriental. No hay que olvidar, finalmente, el activo protagonismo del campesinado en un crecimiento agrícola del que fueron, sin duda, punta de lanza (PASTOR, 1996).

$\mathrm{Si}$ a estos datos añadimos la progresiva diversificación económica que refleja la documentación conservada para estas tempranas fechas (terrae, vineas, pomares, ortales, linares, molinos), podemos intuir el contexto en el que debemos articular los datos que, de forma lenta aunque imparable, está ofreciendo la arqueología para nuestro territorio.

2.2. Las excavaciones arqueológicas que estamos llevando a cabo en la catedral de Santa María de Vitoria-Gasteiz y en su entorno están ofreciéndonos, por vez primera en el País Vasco, un panorama único para conocer la morfología de los asentamientos altomedievales - asignatura pendiente de la arqueología del norte peninsular-. La campaña de 2002 ha enriquecido la visión que ofrecíamos en un avance todavía reciente (AZKARATE, QUIRÓS, 2001). La zona excavada se ubica en el extremo septentrional del cerro donde se asentó la primitiva Gasteiz. Hasta el momento las excavaciones arqueológicas se han llevado a la práctica en un espacio de ca. 1500 metros cuadrados, superficie todavía insuficiente y que no permite efectuar extrapolaciones excesivamente rotundas. Pero, con la prudencia exigida, sí ayuda a entrever algunos aspectos fundamentales de la morfología y configuración de aquellos asentamientos prefeudales.

En este espacio, y tras la campaña del año 2002, parece confirmarse la presencia de un conjunto habitacional bien atestiguado en Europa y constituido por una estructura de mayor porte, interpretada habitualmente como vivienda principal, junto con otras anexas de menor entidad que acostumbran a relacionarse - como ya apuntara Chapelot - bien con lugar de habitación de grupos serviles, bien con estructuras dependientes de carácter productivo.

En el caso de la primitiva Gasteiz, tenemos motivos suficientes, como iremos viendo, para pensar que la gran estructura lígnea que se ubicaba junto a la actual Portada de Santa Ana - todavía parcialmente excavada - pudiera constituir la residencia central de una unidad de explotación constituida por varias cabañas construidas sobre postes, un fond de cabanne de dimensiones notables ${ }^{3}$ (almacén o granero, probablemente), un amplio espacio, llano y despejado, anexo al fondo de cabaña (quizá una era) y, finalmente, una larga roza que parece delimitar otro espacio cerrado (que pudo haber sido utilizado como corral o huerto) (Fig. 1).

${ }^{3}$ Long.: 8,10 m.; anch. máx.: 2,5 m; anch. mín. 2 m. y semiexcavada en la roca ca. $0,8 \mathrm{~m}$. 

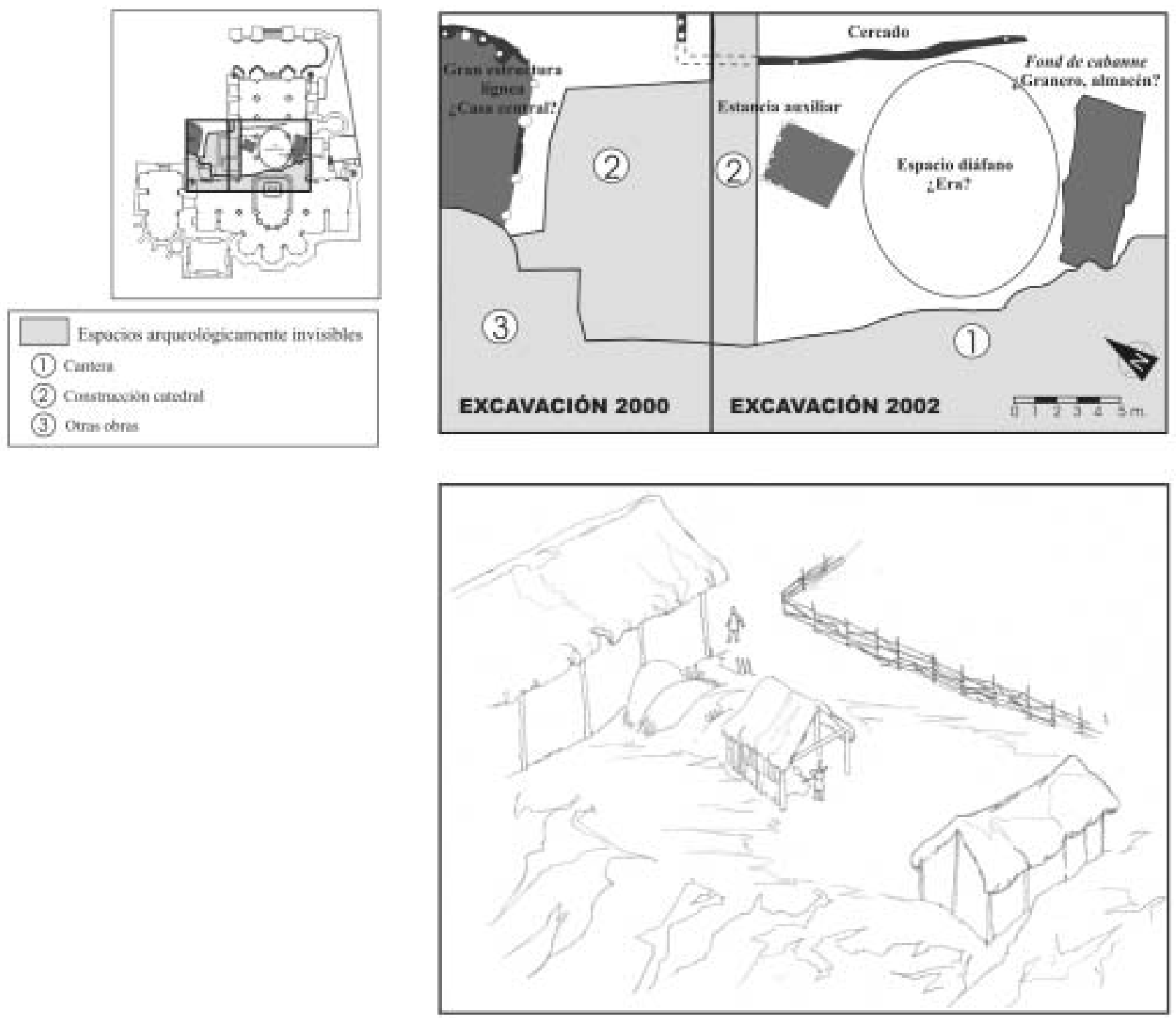

Fig. 1. El altomedievo. Ubicación en planta y restitución en alzado de las estructuras lígneas pertenecientes a los siglos VIII-IX

Los términos casa, orto, corro, era, aparecen vinculadas entre sí desde los más primitivos testimonios recogidos por la documentación escrita altomedieval. Parece evidente que aún no se ha alcanzado la progresiva compactación que caracterizará a los núcleos habitados a partir de la segunda mitad del siglo $\mathrm{X}$.

2.3. Las técnicas constructivas nos remiten, en su totalidad, al uso de materiales perecederos que articulan dos tipos de estructuras: a) Construcciones levantadas a nivel del suelo, descansando sobre postes —unas veces escuadrados, otras no- que se insertan en agujeros y/o rozas perimetrales talladas en la roca a pico o picón. En algunos casos se conser- van todavía pequeñas lajas de piedra que actuarían como calces o cuñas de sujeción. No se constata la existencia de suelos asociados a este modelo, por lo que es probable la utilización de materiales perecederos en su construcción, quizás suelos flotantes de madera. Los alzados se construyen con entramados de ramas manteadas con arcilla y cubiertas de materiales también caducos. b) Estructuras semiexcavadas en la roca natural, de planta trapecial, sin presencia de agujeros de poste o rozas donde fijar los armazones lígneos. A diferencia del primer modelo, en este caso se conservan restos de suelos constituidos por arcilla y fragmentos de roca degradada del propio sustrato geológico, todo ello muy compactado. 
2.4. Las producciones cerámicas reflejan un contexto distinto respecto del que veíamos para las centurias sexta y séptima, aportando un argumento más a favor de ese cambio que, como comentábamos, debió suceder a lo largo del siglo VIII. A finales de esta centuria, en efecto, hacen acto de presencia dos nuevas producciones desconocidas hasta el momento: la cerámica micácea (Grupo V) ${ }^{4}$ y la cerámica desgrasada con silicatos (Grupo VI) $)^{5}$.

Aunque los yacimientos y estratigrafías documentadas en el siglo VIII siguen siendo muy escasos en todo el País Vasco, creemos no equivocarnos mucho al situar la introducción de estas dos producciones en los últimos decenios de este siglo, máxime cuando el registro cerámico de la catedral de Santa María nos muestra ya en los siglos IX y X unos porcentajes para estas producciones cuantitativamente superiores a los de la cerámica grosera. El 84,1\% de los Grupos $\mathrm{V}$ y VI respecto al total de la producción cerámica documentada en los siglos IX y X frente al 10,2\% de la cerámica grosera, refleja la fuerte implantación de aquellos, al mismo tiempo que evidencia un considerable declive de este. De otra parte, la presencia de estas producciones va a provocar un doble efecto en la vajilla doméstica altomedieval, al introducir, por un lado, nuevas formas estandarizadas inexistentes hasta la fecha que amplían el repertorio formal y evidencian cierta especialización funcional (platos, cuencos, cántaros, jarros, etc.); y al desplazar, por otro, a la cerámica grosera de todos los ámbitos funcionales a excepción del culinario, en el que se mantendrá hasta bien entrado el siglo XI.

\footnotetext{
${ }^{4}$ La configuración de los diferentes "grupos» cerámicos ha sido realizada atendiendo a la suma de varios aspectos técnico-compositivos inherentes entre sí, como son el tipo de desgrasante presente en la pasta, la técnica de factura, el revestimiento y el sistema de cocción (AZKARATE, SOLAUN, 2004). El Grupo V, en concreto, hace referencia a una producción identificada por el abundante y fino desgrasante de mica blanca existente en las arcillas, apreciable «de visu». Las producciones elaboradas con este tipo cerámico presentan acabados de una mayor calidad que la cerámica grosera, con vasijas hechas a torno/torneta, de paredes con espesores bastante reducidos y cuidados.

5 Este grupo cerámico es el más representado de los contextos estudiados y presenta producciones con una calidad muy similar a las elaboradas con cerámica micácea, especialmente apropiadas para la obtención de cerámica para cocinar. Compositivamente las diferencias son grandes respecto a la frecuencia y tamaño de los desgrasantes presentes en la arcilla, variando ostensiblemente de unas a otras producciones. A grandes rasgos muestra pastas definidas por el aporte mayoritario de cuarzo acompañado en menor medida por óxidos de hierro y/o cerámicas machacadas (chamotas) —algunos de los cuales han desaparecido dejando poros redondeados-, puntuales cristales de mica y nódulos de cal blancos. Desde el punto de vista técnico fueron elaboradas a torno/torneta.

6 La primera mención de «mercado» en el área estudiada se documenta en el año 998, en que se dice: illa via que vadit ad mercato (GARCÍA DE CORTÁZAR, 1982, 98).
}

En resumen, durante los siglos VIII y X se constata la presencia de dos niveles productivos bien distintos: uno en retroceso, heredero de época tardoantigua y representado por la cerámica grosera elaborada a mano/torneta, con perfiles globulares de tradición romana, decoradas con peinados heterogéneos y escasamente estandarizadas; y otro emergente, nuevo, indicador de importantes cambios en el paisaje económico y social, personificado en la cerámica desgrasada con silicatos (Grupo VI), y la cerámica micácea (Grupo $\mathrm{V}$ ), con formas nuevas, estandarizadas, hechas a torno/torneta y asociadas a la decoración estriada.

El primero de los niveles refleja unas producciones domésticas o familiares, de actividad periódica o estacional, cuyos productos se destinan al autoconsumo o a una red de distribución a escala local. El segundo, en cambio, está denunciando una actividad alfarera nueva, asentada en pequeños talleres rurales dispersos por la región y cuya producción se elabora con vistas a ser comercializada en mercados regionales como los que comenzarán a aparecer en la documentación del siglo $\mathrm{X}^{6}$.

2.5. El siglo décimo supone una consolidación de las tendencias apuntadas en las dos centurias anteriores. Como ha señalado García de Cortázar, se intuye un proceso de progresiva dinamización de los territorios alaveses y, sin duda, tuvo que ver en ello el cese de las incursiones bélicas de los musulmanes y, como consecuencia, la instalación más permanente en el territorio y la explotación más intensa del mismo (1982, 95). Muestra de ello son algunos indicios como la especialización económica que muestran ciertos territorios (cerealística en unos casos, vinícola, salinera o ganadera en otros), la frecuente mención al uso de los molinos, la fundación cada vez más frecuentes de monasterios que comienzan a recibir donaciones pro remedio animae $\mathrm{o}$ pro electione sepulturae, la densificación de los núcleos habitados, etc.

2.6. En la Gasteiz primitiva, los testimonios arqueológicos exhumados son también coincidentes con el dinamismo al que se hacía referencia en el párrafo anterior. En un momento avanzado del siglo $\mathrm{X}$ se introduce una innovación constructiva: la aparición de una técnica de construcción mixta, basada en el uso de zócalos de piedra sobre los que se levantan alzados con entrelazados lígneos manteados de arcilla y reforzados, en ocasiones, con pies derechos de madera embutidos en agujeros de poste. El registro arqueológico no ha aportado restos significativos de teja, por lo que cabe deducir, al igual que en los siglos anteriores, la pervivencia de techumbres con materiales perecederos. En el interior de las estancias hacen acto de presencia compactos 
suelos de tierra batida con uno o varios hogares ejecutados con una técnica muy esmerada ${ }^{7}$.

No existen, sin embargo, cambios aparentes en la organización del espacio. La antigua vivienda lígnea de grandes dimensiones, es substituida por otra de tamaño también notable, aunque construida en técnica mixta. A su alrededor, el espacio se articula de forma similar a la que veíamos en la fase anterior, con las modificaciones constructivas señaladas. Es importante insistir en la permanencia de la vivienda principal como espacio privilegiado que articula las construcciones menores de su entorno. La presencia en el tercero de los suelos de este espacio doméstico de tres hogares contiguos nos está indicando su importancia.

La documentación ofrece algunos datos de interés para este mismo periodo, reflejándonos también una morfología similar a modo de unidad productiva independiente. Es sumamente ilustrativa, a este respecto - por sus paralelos con la organización del espacio que describíamos más arriba-, la mención del año 975 a kasas cum suos solares et suas divisas, et exitos et introitos, et sua hera qui est ad illa porta, cum suo orto et suo korro et suas adiacentias ad toto giro qui ad ipsas casas pertinent (Cart. Valpuesta, 44). La descripción se repite hasta tres veces más en el mismo documento, denunciando la existencia de un modelo común de organización espacial.

No menos interesante, a nuestros efectos, resulta la información tipológica que reflejan algunas menciones documentales cuando se refieren, por ejemplo, a una casa cum sotalo et soperatum et corrale et orto cum suis pomiferis (Cart. San Millán, n. ${ }^{0} 70$, año 956). El material constructivo predominante siguió siendo la madera, tal y como recogen también los testimonios escritos coetáneos: et levabimus matera de quator casas et uno orreo et tectus de tres ecclesias de Valle Posita, et composuimus de ipsa matera casas et eclesial in Villa Merosa, et restaurabimus eas (Cart. Valpuesta, 44, аño 975).

\footnotetext{
7 Tipológicamente pueden ser tanto circulares $(1,15 \mathrm{~m}$. de diámetro) como rectangulares $(1,30 \mathrm{~m} .1,00 \mathrm{~m}$.) o cuadrangulares $(1,00 \mathrm{~m}, 0,90$ $\mathrm{m}$.). En cualquiera de los casos, su técnica de ejecución es casi siempre muy esmerada. Se procede, en primer lugar, a su excavación en el suelo de la habitación correspondiente; se prepara, a continuación, una base constituida generalmente por cantos de río — bien solos bien mezclados con fragmentos cerámicos o escoria - que se recubre cuidadosamente de arcilla muy decantada. En ciertas ocasiones se protege el hogar con un resalte perimetral que lo aísla del suelo circundante. En otras, este aislamiento se consigue con un simple círculo de piedras.

8 En este muro destaca un pequeño avance rectangular situado aproximadamente en la zona central del paramento, cuya funcionalidad pudiera corresponderse con una estructura de acceso que facilitara la entrada a la vivienda.
}

\section{EL CAMBIO DE MILENIO}

3.1. El cambio de milenio - por usar un referente simbólico- viene marcado por algunos aspectos históricos de la máxima importancia que dejarán huella, obviamente, tanto en la morfología de los asentamientos como en las estructuras productivas que los mantenían. Las investigaciones arqueológicas constatan también transformaciones de gran calado. A partir del siglo XI, en efecto, ocurren cambios importantes en la organización espacial del extremo septentrional de la primitiva Gasteiz, cambios que reflejan una nueva voluntad organizativa del espacio, un nuevo planteamiento urbanístico que resumiremos ahora muy brevemente y que será objeto de descripción pormenorizada en la publicación anunciada. Su documentación arqueológica y su segura adscripción cronológica a la primera mitad del siglo XI alcanzan un notable significado histórico.

Lo más significativo, quizá, de la transformación a la que nos referimos sea la aparición, por primera vez, de la calle como articuladora del nuevo modelo. Para su trazado se procedió previamente: a) al arrasamiento de las estructuras que se interponían en su trazado; b) a la nivelación y preparación del terreno con el acarreo de toneladas de tierra procedentes de algún lugar próximo. Tras esta importante obra de preparación, la morfología del lugar se modificó sustancialmente (Fig. 2). Los elementos más significativos de la nueva configuración serán los siguientes:

a) Una vivienda de dimensiones notables que ocupa el mismo emplazamiento que veíamos para la gran estructura lígnea del siglo IX y la estructura construida con técnica mixta que existió en el siglo $\mathrm{X}$. Construida siguiendo las innovaciones técnicas desarrolladas por los constructores de las casas sobre zócalo de piedra, de esta estructura conservamos únicamente sus límites septentrional y occidental ${ }^{8}$, por lo que resulta imposible determinar de forma definitiva su planta y dimensiones. En su interior se han documentado un suelo de arcilla apisonada y un hogar circular.

b) A pocos metros al norte de la estructura descrita (y esta proximidad es, por sí misma, suficientemente significativa sobre la creciente densificación y compactación del tejido urbano) se va a levantar otra vivienda con una técnica constructiva conocida en Europa pero que se documenta por primera vez en el asentamiento de Gasteiz y que articula la estructura construida sobre durmientes de madera y pies derechos encastrados en ellos. Conservada de manera parcial al haber sido afectada por actividades posteriores, resulta imposible establecer su planta, si bien sorprende por sus dimensiones. En lo que se conserva tiene, al menos, una longitud de $c a .11$ metros y una anchura de $c a .10$ metros. Un medianil lígneo divide la vivienda en dos estancias: una al sur, de 24 metros cuadrados conservados, en 

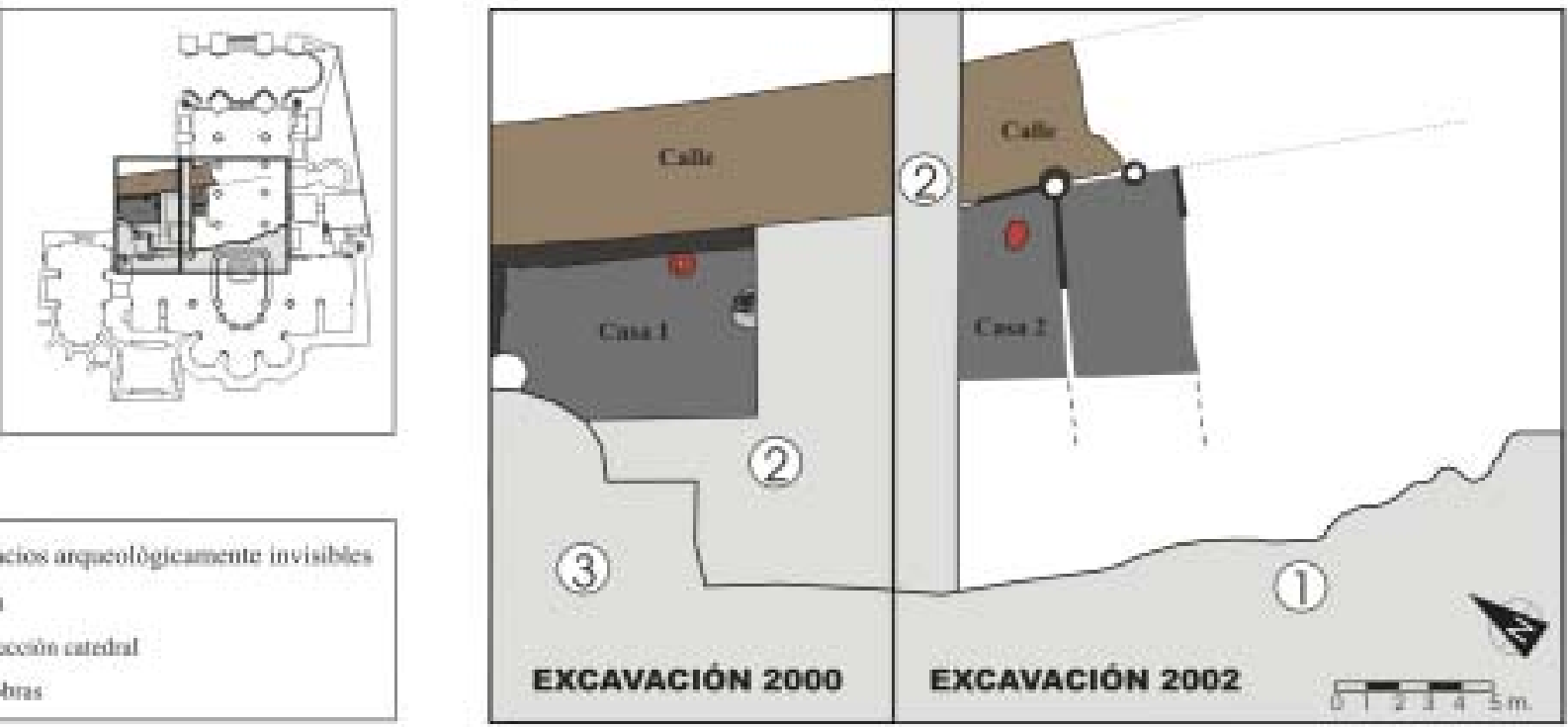

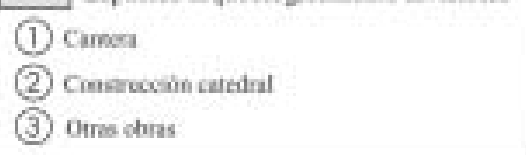

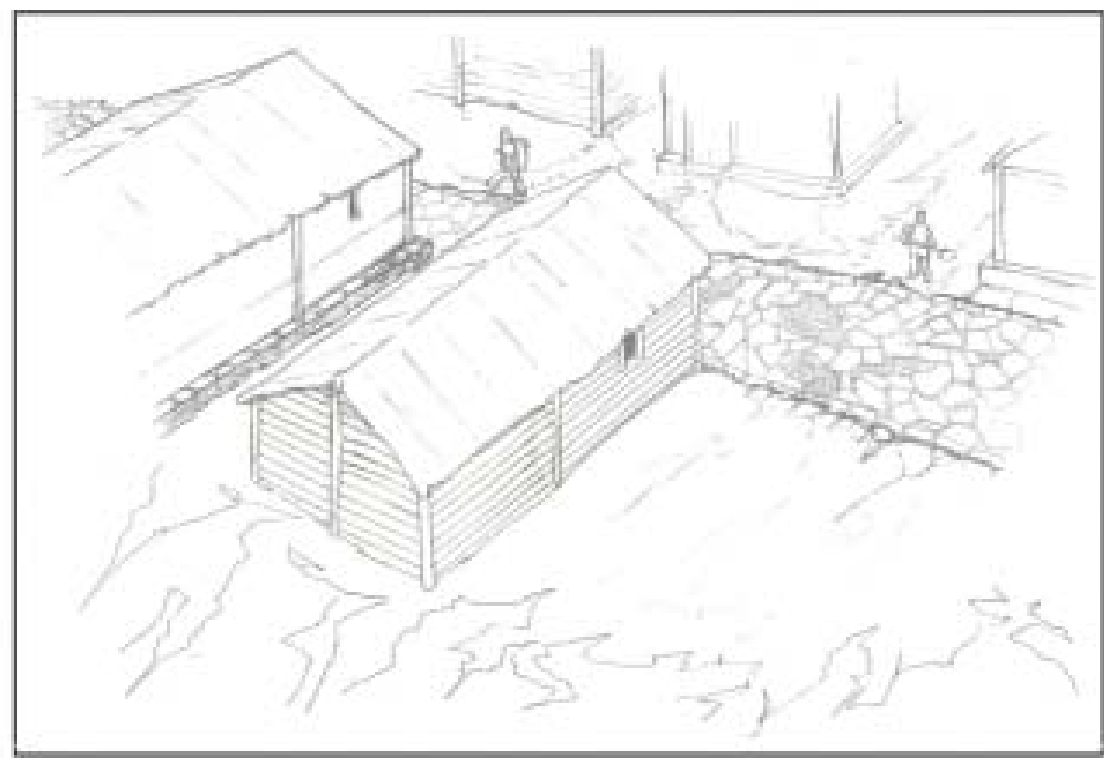

Fig. 2. El cambio de milenio. Ubicación en planta y restitución en alzado del nuevo urbanismo documentado en la primera mitad del siglo xl, una vez efectuada la importante obra de nivelación y preparación del terreno

cuyo interior destaca un suelo de cal y un hogar, delimitado al oeste por una pequeña estructura rectangular de adobes ${ }^{9}$; y otra al norte, peor conservada, de al menos 35 metros cuadrados, cuyo interior carece de cualquier tipo de elemento diferenciador.

c) La urbanización del espacio se completa con la creación de una calle en dirección noroeste-sureste, con

${ }_{9}$ Por el momento y a la espera de un estudio más detallado, la hipótesis más lógica en cuanto a su funcionalidad parece ser la de separar el fuego del hogar de los alzados lígneos de la estancia, al mismo tiempo que crea un espacio contenedor para las cenizas sobrantes del hogar. una anchura de 4 metros. Aunque su estado de conservación es bastante deficiente, en algunos puntos se ha podido registrar una cama de preparación, compuesta por gran cantidad de mampuestos irregulares, sobre la que se asienta un enlosado de lajas calizas bien aparejadas que constituyen el suelo de uso.

3.2. El proceso de diversificación cerámico iniciado en el periodo anterior se va a mostrar con igual o mayor fuerza en la primera mitad del siglo XI, al aparecer cuatro nuevos tipos cerámicos que se sumarán a los ya documentados anteriormente. Nos referimos a la cerámica desgrasada con 
calcita, silicatos y mica (Grupo III) ${ }^{10}$, la cerámica espatulada (Grupo IV) $)^{11}$, la cerámica pintada (Grupo VIII) ${ }^{12}$ y la cerámica rugosa de pastas claras (Grupo $\mathrm{X})^{13}$.

Sin embargo, algunas de estas nuevas producciones no parecen responder a los sistemas productivos descritos para los siglos VIII y X, ya que presentan unas características técnicas y cuantitativas sustancialmente diferentes. Así, los grupos IV, VIII y X poseen unos porcentajes anecdóticos con respecto al resto de tipos cerámicos (un 1,2\%, 0,4\% y $0,8 \%$ respectivamente, frente al $24,4 \%$ ó $57,6 \%$ de los grupos $\mathrm{V}$ y VI), además de mostrar una mayor calidad técnica en su factura, que inducen a pensar en producciones elaboradas por artesanos locales más especializados e incluso importadas de otras zonas.

Esta diversificación y especialización de la producción va a manifestarse asimismo en el repertorio formal, extremadamente variado y estandarizado, surgiendo un buen número de tipos de ollas, platos, orzas, etc., e introduciéndose nuevas series cerámicas como los recipientes provistos de una piquera de puente vertedora (la sitra catalana) o el lebrillo.

Nos encontramos, por tanto, ante un nuevo modelo productivo que viene a sumarse a los ya existentes, consolidado en el siglo XII con la aparición de las primeras producciones vidriadas, en concreto de la cerámica con vedrío espeso mate (Grupo XI $)^{14}$. Sin duda, la calidad de esta

10 Grupo caracterizado por unas pastas groseras de tacto y textura rugosa, en las que los desgrasantes de calcita y cuarzo se combinan con mica blanca de fino y medio tamaño. Elaborado en un ambiente de combustión completamente reductor parece estar confeccionado a torno/torneta, aunque el tratamiento superficial de alisado efectuado mediante un paño impide apreciar bien sus rasgos.

11 Nuevo grupo cerámico de pastas duras y decantadas, en la que se observan finos desgrasantes bien repartidos por la pasta: micas, cuarzos y partículas negras de difícil identificación. La factura responde a la técnica denominada a mano/torneta, destacando el espatulado aplicado a toda la superficie exterior del recipiente, que proporciona un característico brillo y tacto jabonoso.

12 Desde el punto de vista compositivo el soporte de este tipo de producciones se asemeja mucho al Grupo VI «Cerámica oxidante desgrasada con silicatos", aunque se observa una mayor decantación y dureza en las pastas, así como una disminución del tamaño de los desgrasantes. La principal diferencia viene marcada por la aplicación, sobre su superficie, de gruesos trazos en zig-zag pintados en rojo.

13 Este grupo cerámico presenta una gran calidad técnica, con recipientes de paredes muy delgadas en las que se observa un excelente torneado y un buen control de la combustión y temperatura de cocción, realizada en ambientes completamente oxidantes, con un característico color blanco.

14 El recubrimiento vítreo se aplica de manera parcial al vaso — principalmente al exterior, aunque aparecen fondos cubiertos también al interior-, con un acuchillado previo de la pasta para su aligeramiento. Se tratan de vidriados plúmbeos, bien adheridos y bastante espesos, con barnices monocromos de tonalidad amarillo oliva (2.5YR 6/6) o marrón oliva suave (2.5YR 5/6) poco brillantes. Respecto a la técnica de modelado, en todos los casos se aprecia el uso del torno. producción, así como su exigua representatividad (3\% del total), nos está hablando de cerámicas importadas de otros ámbitos geográficos, elaboradas en verdaderos talleres especializados, quizás urbanos asentados en el valle medio del Ebro y con escasa demanda aún en zonas rurales del cantábrico.

Son significativas, a este respecto, algunas referencias documentales que mencionan explícitamente redes de comercio a larga distancia ya consolidadas. Es el caso del Fuero de Miranda que, por estas fechas (1099), se está refiriendo a omnes homines de terra lucronii, aut de nagera, aut de rioga, qui voluerint transire mercaturas versus alauam... aut omnes de alana aut de alia terra quacumque versus locronium aut ad nagaram aut riogam, transerit per mirandam (Fuero de Miranda de Ebro, ed. F. Cantera Burgos, Madrid, 1945: 56).

Parece claro, ya para terminar, que el nuevo milenio llegaba anunciando cambios de gran envergadura que no podemos desarrollar en el espacio de este breve artículo. Si es cierto que una imagen vale más que mil palabras, la figura que adjuntamos (Fig. 3) debe ser suficientemente expresiva para reflejar la importancia de las transformaciones que se avecinaban y que acabaron por convertir la vieja aldea campesina primero en un asentamiento sólidamente fortificado y, más adelante, en una villa que ha mantenido su prosperidad hasta nuestros días.

\section{Bibliografía}

Azkarate A., 1988, Arqueología cristiana. De la Antigüedad Tardía en Álava, Guipúzcoa y Vizcaya, Vitoria-Gasteiz.

AzKarate A., 2004, Las Reihengräberfelder al sur de los Pirineos occidentales, en Homenaje a Th. Ulbert, (e.p.).

Azkarate A., Quirós, J. A, 2003, Arquitectura doméstica altomedieval en la Península Ibérica. Reflexiones a partir de las excavaciones arqueológicas de la Catedral de Santa María de Vitoria-Gasteiz, País Vasco, Archeologia Medieval, XXVIII, 2001, pp. 8ss.

Azkarate A., Núnez J., Solaun, J. L., 2003, Materiales y contextos cerámicos de los siglos VI al X en el País Vasco, Anejos del Archivo Espanol de Arqueología XXX, pp. 319ss.

AzKarate A., SOlaun, J. L., 2004, Investigaciones arqueológicas en el núcleo fundacional de Vitoria-Gasteiz. Primeros avances sobre poblamiento $e$ indicadores cronológicos cerámicos, Vitoria (e.p.).

Chapelot J., Fossier R., 1980, Le village et la maison au Moyen Age, Paris.

GARCÍA CAMINO I., 1989, La cerámica medieval no esmaltada en la vertiente marítima del País Vasco: Los territorios de Bizkaia y Gipuzkoa, en La cerámica medieval en el Norte y Noroeste de la Península Ibérica. Aproximación a su estudio, León, pp. 87ss.

GARCÍA DE CORTÁZAR J. A., 1982, La sociedad alavesa medieval antes de la concesión del fuero de Vitoria, en Vitoria en la Edad Media, Actas del I Congreso de Estudios Históricos, Vitoria-Gasteiz, 1981, VitoriaGasteiz, pp. 89ss.

Halsall G., 1995, Settlement and social organization. The Merovingian region of $M e t z$, Cambridge.

La Rocca C., 1998, Donare, distribuire, spezzare. Pratiche di conservazione della memoria e dello status in Italia tra VIII e IX secolo, en Sepol- 

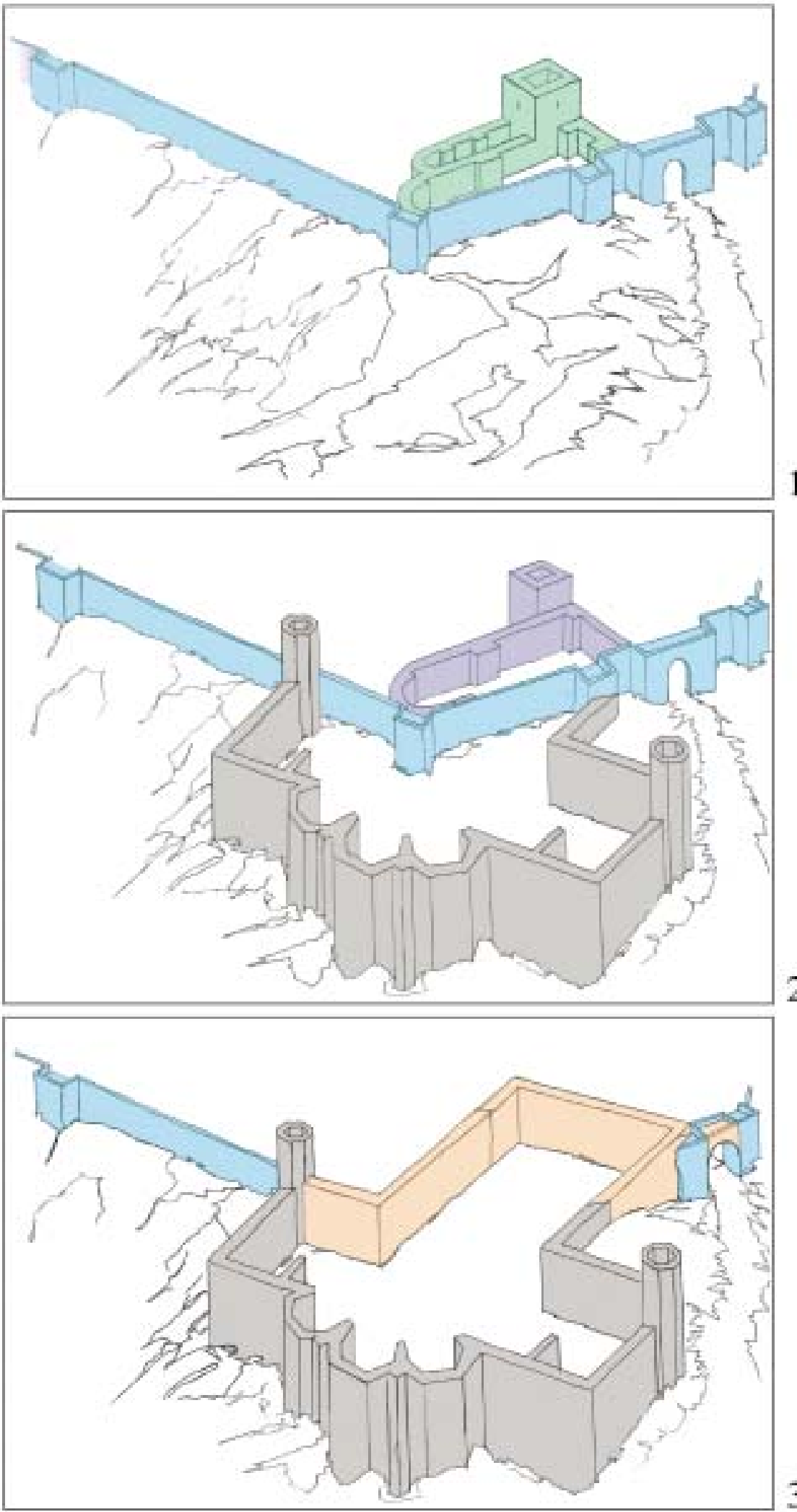

3

Fig. 3. Evolución del paisaje urbanístico en los siglos XII y XIII.

1. Sobre el mismo espacio que veíamos en la fase anterior se procederá a la construcción de una potente muralla pétrea a la que, posteriormente, se adosará intramuros una iglesia.

2. Tras el incendio de 1202 se procede a la reconstrucción de la anterior iglesia y a la edificación extramuros de un gran templo, que con el tiempo acabará transformándose en la actual catedral de Santa María.

3. Solamente cuando la construcción del nuevo templo avance hacia los pies se procederá al derribo de la iglesia y muralla que obstaculizaban su desarrollo. 
ture tra IV e VIII secolo, 7. ${ }^{\circ}$ Seminario sul tardo antico e L'alto medievo in Italia centro settentrionale, Gardone Riviera 24-26 ottobre 1996 (a cura di G. P. Brogiolo e G. C. Wataghin), Documenti de Archeologia 13 , pp. 77 ss.

Martínez J. M., Plata A., Solaun J. L., 2001, Materiales cerámicos, en Catedral de Santa María de Vitoria-Gasteiz. Plan Director de Restauración, T. II, Vitoria-Gasteiz, pp. 170ss.

Pastor E., 1996, Castilla en el tránsito de la Antigüedad al Feudalismo. Poblamiento, poder político y estructura social del Arlanza al Duero (siglos VII-XI), Valladolid.

PEACOCK, D.P.S., 1982, Pottery in the roman world: an etnoarchaeological approach, London.

Pérez Soler M. D., 1970, Cartulario de Valpuesta, Valencia.

Perin P., 1998, Possibilités et limites de l'interprétation sociale des cimitières mérovingiens, Antiquités Nationales, 30, pp. 169ss.

SÁENZ DE URTURI F., 1989, La cerámica medieval no esmaltada en yacimientos alaveses, en Las cerámicas medievales del Norte y Noroeste de la Península Ibérica, León, pp. 53ss.

Ubieto, A., 1976, Cartulario de San Millán de la Cogolla (759-1076), Valencia.

VALENTI M., 1996, La Toscana tra VI e IX secolo. Città e campagna tra fine dell'età tardoantica ed altomedievo, en La fine delle ville Romane: Trasformazioni nelle campagne tra tarda antichità e alto medievo, $1 .^{\circ}$ Convegno Archeologico del Garda, Gardone Riviera (Brescia), 14 ottobre 1995, (a cura di G. P. Brogiolo), Documenti de Archeologia 11 , pp. 81ss.

WICKHAM C., 1989, La otra transición: del mundo antiguo al feudalismo, Studia Historica. Historical Medieval VII, pp. 7ss. 